\title{
Shape-Controlled Generation of Gold Nanoparticles Assisted by Dual-Molecules: The Development of Hydrogen Peroxide and Oxidase-Based Biosensors
}

\author{
Chifang Peng, Xiaohui Duan, Zhengjun Xie, and Chunli Liu \\ State Key Laboratory of Food Science and Technology, School of Food Science and Technology, Jiangnan University, Wuxi 214122, China \\ Correspondence should be addressed to Chifang Peng; pcf@jiangnan.edu.cn
}

Received 29 June 2014; Accepted 5 September 2014; Published 13 October 2014

Academic Editor: Marinella Striccoli

Copyright (C) 2014 Chifang Peng et al. This is an open access article distributed under the Creative Commons Attribution License, which permits unrestricted use, distribution, and reproduction in any medium, provided the original work is properly cited.

\begin{abstract}
With the assist of dual-molecules, 2-(N-morpholino)ethanesulfonic acid (MES) and sodium citrate, gold nanoparticles (GNPs) with different shapes can be generated in the $\mathrm{H}_{2} \mathrm{O}_{2}$-mediated reduction of chloroauric acid. This one-pot reaction can be employed to sensitively detect $\mathrm{H}_{2} \mathrm{O}_{2}$, probe substrates or enzymes in oxidase-based reactions as well as prepare branched GNPs controllably. By the "naked eye," $20 \mu \mathrm{M} \mathrm{H}_{2} \mathrm{O}_{2}, 0.1 \mu \mathrm{M}$ glucose, and $0.26 \mathrm{U} / \mathrm{mL}$ catalase could be differentiated, respectively. By spectrophotometer, the detected limits of $\mathrm{H}_{2} \mathrm{O}_{2}$, glucose, and catalase were $1.0 \mu \mathrm{M}, 0.01 \mu \mathrm{M}$, and $0.03 \mathrm{U} / \mathrm{mL}$, respectively, and the detection linear ranges for them were 5.0-400 $\mu \mathrm{M}, 0.01-0.3 \mathrm{mM}$, and $0.03-0.78 \mathrm{U} / \mathrm{mL}$, respectively. The proposed "dual-molecules assist" strategy probably paves a new way for the fabrication of nanosensors based on the growth of anisotropic metal nanoparticles, and the developed catalase sensor can probably be utilized to fabricate ultrasensitive ELISA methods for various analytes.
\end{abstract}

\section{Introduction}

Gold nanoparticles (GNPs) possess distinct physical and chemical attributes that make them excellent scaffolds for the fabrication of novel chemical and biological sensors [1]. Interestingly, some unique sensors based on GNP enlargement of GNP seeds have been developed, such as colorimetric sensors for enzymes and substrates in biocatalyzed reactions [2] and light scattering signal enhancer in scanometric immunoassay [3]. Recently, the generation of GNPs has also been utilized to develop some novel sensors, such as chemiluminescence sensor based on DNA structure catalyzing the formation of GNPs [4] that produce gold nanoshells for detecting hydrogen peroxide scavenging activity [5] and liquid crystal biosensors based on enzymatic deposition of GNPs [6].

The accurate and rapid determination of $\mathrm{H}_{2} \mathrm{O}_{2}$ is of practical importance due to its application in food, pharmaceutical, clinical, industrial, and environmental analysis [5,7]; $\mathrm{H}_{2} \mathrm{O}_{2}$ is generally acknowledged to be an oxidative agent. However, it has been reported to be able to reduce $\mathrm{HAuCl}_{4}$ to synthesize AuNPs in a broad pH range [8]. Recently, de la Rica et al. described a visual $\mathrm{H}_{2} \mathrm{O}_{2}$ sensor, based on which an ultrasensitive enzyme-linked immunosorbent assay (ELISA) for prostate specific antigen was developed. The above visual $\mathrm{H}_{2} \mathrm{O}_{2}$ sensor was based on $\mathrm{H}_{2} \mathrm{O}_{2}$-mediated generation of GNPs in MES buffer. An abrupt change in the solution color from red to blue happened when the concentration of $\mathrm{H}_{2} \mathrm{O}_{2}$ was under a cut-off value $[9,10]$. Nevertheless, this novel method cannot be utilized to quantitatively detect targets. It also should be noted that gold precursors have to be prepared first by using MES as a reducing agent in this method [11]. In this step, unstable GNPs aggregates are easily produced [12], which will bring about difficulty and inconvenience in practical applications. Since the stability of GNPs is affected by many factors, such as reducing agents, surfactants [13], the above $\mathrm{H}_{2} \mathrm{O}_{2}$ sensor based on GNPs generation probably can be improved by adjusting these additives.

Herein, we utilized dual-molecules, sodium citrate $\left(\mathrm{Na}_{3} \mathrm{Cit}\right)$ and MES, to control the generation of GNPs in the $\mathrm{H}_{2} \mathrm{O}_{2}$-mediated reduction of $\mathrm{AuCl}_{4}^{-}$. It was found that this $\mathrm{H}_{2} \mathrm{O}_{2}$-mediated GNPs generation can be utilized to qualitatively detect $\mathrm{H}_{2} \mathrm{O}_{2}$ and prepare branched GNPs. Based on the above discovery, a sensitive and simple $\mathrm{H}_{2} \mathrm{O}_{2}$ sensor by the naked eye was developed. Catalase and glucose were 
taken as examples to show the applications of this $\mathrm{H}_{2} \mathrm{O}_{2}$ sensor.

\section{Experimental Section}

Reagents. The reagents, $\mathrm{HAuCl}_{4}$, sodium citrate, MES, and catalase (C1345), were purchased from Sigma-Aldrich. Glucose and GOD (G109029) were purchased from Aladdin Reagent Company (Shanghai). High-purity water (Milli-Q water) was used throughout the experiments. All other reagents are of analytical grade unless otherwise stated.

Effects of Buffers on the Generation of GNP Solutions. $3 \mu \mathrm{L}$ of $\mathrm{HAuCl}_{4}(30 \mathrm{mM}), 6 \mu \mathrm{L}$ of $\mathrm{Na}_{3} \mathrm{Cit}(80 \mathrm{mM})$ were mixed thoroughly with $91 \mu \mathrm{L}$ MES (2.0 mM, pH 6.5), phosphate buffer $(2.0 \mathrm{mM}, \mathrm{pH} 6.5)$ or tris-(hydroxymethyl)aminoethane buffer (Tris, $2.0 \mathrm{mM}$, pH 6.5) buffer (2.0 mM, pH =6.5), were mixed thoroughly; then $100 \mu \mathrm{L}$ of $\mathrm{H}_{2} \mathrm{O}_{2}$ was added and incubated at ambient temperature for $10 \mathrm{~min}$. $\mathrm{Na}_{3}$ Cit or MES was replaced by the same volume of ultrapurified water in the above reaction to investigate their effects. In addition, varied concentrations of $\mathrm{Na}_{3} \mathrm{Cit}(20,40,80$, and $120 \mathrm{mM})$ were compared in the above reaction system with $\mathrm{HAuCl}_{4}$, MES, and $\mathrm{H}_{2} \mathrm{O}_{2}$.

Characterization of GNPs. Absorbance spectra were measured by microplate spectrophotometer (Bio-Tek PowerWave XS). Size distribution and zeta potential of GNPs were measured by Zetasizer Nano ZS (Malvern) after the GNPs were produced within $15 \mathrm{~min}$. Transmission electron microscopy (TEM) images were obtained using JEOL JEM-2100 operating at an acceleration voltage of $200 \mathrm{kV}$.

Detection of $\mathrm{H}_{2} \mathrm{O}_{2}$. In a representative procedure, $3 \mu \mathrm{L}$ of $\mathrm{HAuCl}_{4}(20 \mathrm{mM}), 6 \mu \mathrm{L}$ of $\mathrm{Na}_{3} \mathrm{Cit}(40 \mathrm{mM})$, and $91 \mu \mathrm{L}$ of MES buffer $(2.0 \mathrm{mM}, \mathrm{pH}=6.5)$ were mixed thoroughly; then $100 \mu \mathrm{L}$ of $\mathrm{H}_{2} \mathrm{O}_{2}$ was added. After incubating at ambient temperature for $10 \mathrm{~min}$, absorbance spectra were recorded.

Detection of Catalase. $50 \mu \mathrm{L}$ of catalase (0-40 nM) and $50 \mu \mathrm{L}$ of $\mathrm{H}_{2} \mathrm{O}_{2}(400 \mu \mathrm{M})$ were mixed and incubated at ambient temperature for $20 \mathrm{~min}$. Then the reaction solutions were added into the mixture of $3 \mu \mathrm{L}$ of $\mathrm{HAuCl}_{4}(20 \mathrm{mM}), 6 \mu \mathrm{L}$ of $\mathrm{Na}_{3} \mathrm{Cit}(40 \mathrm{mM})$, and $91 \mu \mathrm{L}$ of $\mathrm{MES}(2.0 \mathrm{mM}, \mathrm{pH} 6.5)$. After incubating for another $10 \mathrm{~min}$, absorbance spectra were recorded.

Detection of Glucose. $50 \mu \mathrm{L}$ of GOx $(50 \mu \mathrm{g} / \mathrm{mL})$ and $50 \mu \mathrm{L}$ of glucose $(0-30 \mathrm{mM})$ were mixed first and incubated at ambient temperature for $20 \mathrm{~min}$. Then the reaction solutions were added into the mixture of $3 \mu \mathrm{L}$ of $\mathrm{HAuCl}_{4}(20 \mathrm{mM})$, $6 \mu \mathrm{L}$ of $\mathrm{Na}_{3} \mathrm{Cit}(40 \mathrm{mM})$, and $91 \mu \mathrm{L}$ of $\mathrm{MES}$ (2.0 mM, pH 6.5). After incubating for another $10 \mathrm{~min}$, absorbance spectra were recorded.

\section{Results and Discussion}

3.1. Development of $\mathrm{H}_{2} \mathrm{O}_{2}$ Sensor. Usually, MES can reduce $\mathrm{HAuCl}_{4}$ and produce a blue color [12]. After $\mathrm{H}_{2} \mathrm{O}_{2}$ was added

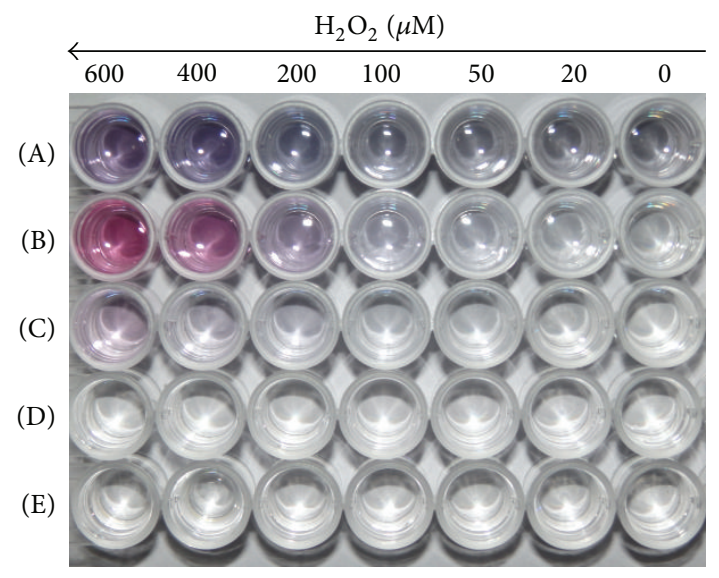

(a)

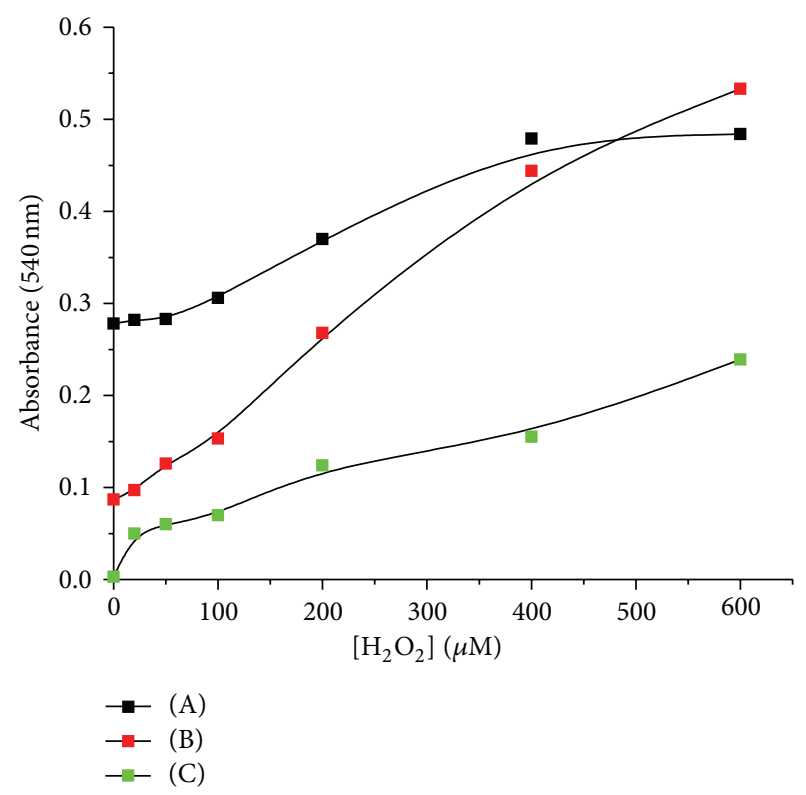

(b)

FIGURE 1: GNP solutions generated in different buffers. (a) Photograph showing the reaction solution. (b) Absorbance values $(540 \mathrm{~nm})$ of GNP solutions as a function of $\mathrm{H}_{2} \mathrm{O}_{2}$ concentration. Reaction condition: (A) $0.45 \mathrm{mM} \mathrm{HAuCl}_{4}$ and $1.0 \mathrm{mM}$ MES ( $\mathrm{pH}=$ 6.5); (B) $0.45 \mathrm{mM} \mathrm{HAuCl}_{4}, 2.4 \mathrm{mM}$ sodium citrate, and $1.0 \mathrm{mM} \mathrm{MES}$ $(\mathrm{pH}=6.5) ;(\mathrm{C}) 0.45 \mathrm{mM} \mathrm{HAuCl}_{4}, 2.4 \mathrm{mM}$ sodium citrate, and water; (D) $0.45 \mathrm{mM} \mathrm{HAuCl}_{4}, 2.4 \mathrm{mM}$ sodium citrate, and $1.0 \mathrm{mM} \mathrm{PB} \mathrm{(pH} \mathrm{=}$ 6.5); (E) $0.45 \mathrm{mM} \mathrm{HAuCl}_{4}, 2.4 \mathrm{mM}$ sodium citrate, and $1.0 \mathrm{mM}$ Tris $(\mathrm{pH}=6.5)$.

to the mixture of $\mathrm{MES}$ and $\mathrm{HAuCl}_{4}$, only high concentration of $\mathrm{H}_{2} \mathrm{O}_{2}(200 \mu \mathrm{M})$ could be differentiated by the naked eye (Figure 1(a)). The absorbance intensity of the GNPs solution increased with the increasing concentration of $\mathrm{H}_{2} \mathrm{O}_{2}$ in a very narrow range of 100-400 $\mu \mathrm{M}$ (Figure 1(b)). Thus, the reaction was substoichiometric and not sensitive for sensing $\mathrm{H}_{2} \mathrm{O}_{2}$ mainly due to the formed unstable aggregated gold nanostructures (See Figure S1 at Supplementary Material available online at http://dx.doi.org/10.1155/2014/576082). As expected, sodium citrate $\left(\mathrm{Na}_{3} \mathrm{Cit}\right)$ can act as stabilizer to improve 
the sensing performance against $\mathrm{H}_{2} \mathrm{O}_{2}$. With the addition of $\mathrm{Na}_{3} \mathrm{Cit}(20 \mathrm{mM})$ into MES- $\mathrm{AuCl}_{4}^{-}$solution, the MES$\mathrm{Na}_{3} \mathrm{Cit}-\mathrm{AuCl}_{4}{ }^{-}$reaction solution without $\mathrm{H}_{2} \mathrm{O}_{2}$ became colorless. The result shows that $\mathrm{Na}_{3} \mathrm{Cit}$ can act as an "inhibitor" of the reduction of $\mathrm{AuCl}_{4}{ }^{-}$by MES to some extent. As a result, $20 \mu \mathrm{M} \mathrm{H}_{2} \mathrm{O}_{2}$ could be differentiated by the naked eye (Figure 1(a)). More importantly, the color of GNPs deepened gradually as the concentration of $\mathrm{H}_{2} \mathrm{O}_{2}$ increased in the range of $0-600 \mu \mathrm{M}$. This result was consistent with the nearly linear plot of the absorbance values of the produced GNPs solutions versus $\mathrm{H}_{2} \mathrm{O}_{2}$ concentrations in the range from $0 \mu \mathrm{M}$ to $600 \mu \mathrm{M}$ (Figure 1(b)). Interestingly, $\mathrm{Na}_{3} \mathrm{Cit}$ also can assist the $\mathrm{H}_{2} \mathrm{O}_{2}$-mediated reduction of $\mathrm{AuCl}_{4}{ }^{-}$although the reduction is very weak (Figures 1(a)-1(b)). $\mathrm{H}_{2} \mathrm{O}_{2}$ cannot reduce $\mathrm{AuCl}_{4}{ }^{-}$ into GNPs in other common buffers containing $\mathrm{Na}_{3} \mathrm{Cit}$, such as phosphate buffer or tris(hydroxymethyl)aminomethane buffer (Figure 1(a)). The above comparison suggests that MES and $\mathrm{Na}_{3}$ Cit together can work synergistically, leading to a more specific reduction of $\mathrm{AuCl}_{4}^{-}$by $\mathrm{H}_{2} \mathrm{O}_{2}$ than only MES.

$\mathrm{Na}_{3}$ Cit can stabilize the GNPs generated to some extent because the produced GNPs in the $\mathrm{AuCl}_{4}{ }^{-} / \mathrm{MES} / \mathrm{H}_{2} \mathrm{O}_{2}$ reaction became smaller after adding $0.4 \mathrm{mM} \mathrm{Na}_{3} \mathrm{Cit}$. When $400 \mu \mathrm{M} \mathrm{H}_{2} \mathrm{O}_{2}$ was added into $\mathrm{HAuCl}_{4}$-MES- $\mathrm{Na}_{3}$ Cit solution, the average hydrodynamic diameter of produced GNPs was $49 \mathrm{~nm}$, while the bigger GNPs (mean hydrodynamic diameter $=108 \mathrm{~nm}$ ) assembled by smaller GNPs were obtained in the absence of $\mathrm{Na}_{3} \mathrm{Cit}$ (Figure S1). With the added $\mathrm{Na}_{3} \mathrm{Cit}$ being increased from $40 \mathrm{mM}$ to $120 \mathrm{mM}$, the produced GNPs showed almost the same color and the plots of the absorbance intensity versus $\mathrm{H}_{2} \mathrm{O}_{2}$ concentration highly overlapped (Figure S2). But after decreasing the concentration of $\mathrm{Na}_{3} \mathrm{Cit}$ to $10 \mathrm{mM}$, the absorbance intensity corresponding to $400 \mu \mathrm{M}$ $\mathrm{H}_{2} \mathrm{O}_{2}$ became occasionally lower than that corresponding to $200 \mu \mathrm{M}$. This result is due to the fact that the produced high concentration of GNPs solution does not have enough $\mathrm{Na}_{3} \mathrm{Cit}$ and easily forms aggregate. Since the $\mathrm{pH}$ value and concentration of MES probably change the reduction ability of MES, we varied the $\mathrm{pH}$ value and concentration of MES to choose the best $\mathrm{pH}$ and concentration of MES. The best $\mathrm{pH}$ value was found to be 6.5 (Figure S3). The MES concentration also affects the performance of the above $\mathrm{H}_{2} \mathrm{O}_{2}$ sensor probably due to the changed ratio of MES to $\mathrm{Na}_{3}$ Cit (Figure S4).

In a representative condition, GNPs solutions with different tonality could be obtained depending on the concentration of $\mathrm{H}_{2} \mathrm{O}_{2}$ (Figure 2(a)). Light blue solutions corresponding to lower concentration of $\mathrm{H}_{2} \mathrm{O}_{2}(20-100 \mu \mathrm{M})$ were obtained, and purple to wine red solutions corresponding to higher concentration of $\mathrm{H}_{2} \mathrm{O}_{2}(200-600 \mu \mathrm{M})$ were produced. As a result, $20 \mu \mathrm{M} \mathrm{H}_{2} \mathrm{O}_{2}$ can be detected by the naked eye. Colorimetric assay showed that the maximum absorbance values increased and the GNPs surface plasmon resonance (SPR) peak blue-shifted from $560 \mathrm{~nm}$ to $540 \mathrm{~nm}$ as the concentration of $\mathrm{H}_{2} \mathrm{O}_{2}$ increased (Figure 2(b)). The blueshift of SPR peak in this system was opposite to the redshift usually observed in seed-mediated gold enlargement systems $[2,5]$. After the concentration of $\mathrm{H}_{2} \mathrm{O}_{2}$ decreased to $100 \mu \mathrm{M}$, obviously broadening of the SPR peaks was observed. This abrupt change of SPR peaks was consistent with the change of red color to light blue color.

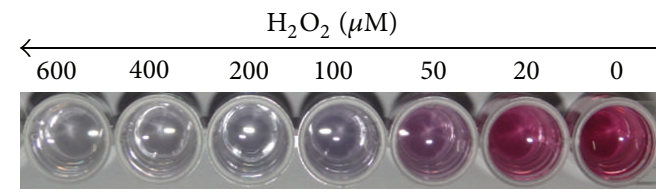

(a)

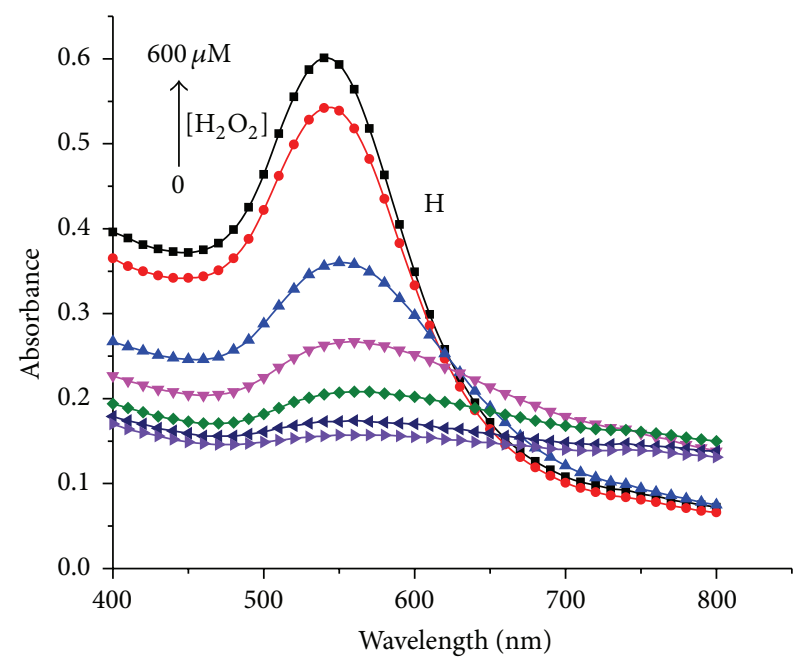

(b)

FIGURE 2: Generation of GNP solutions with different colors depends on the concentration of $\mathrm{H}_{2} \mathrm{O}_{2}$. (a) Photograph showing the generation of nanoparticle solutions with different colors and intensities after $10 \mathrm{~min}$. (b) Absorbance spectra of GNPs generated with different concentration of $\mathrm{H}_{2} \mathrm{O}_{2}$. From bottom to up: 0, 50, 100, 200,400 , and $600 \mu \mathrm{M}$.

Because MES (1.0 mM) was excessive to $\mathrm{AuCl}_{4}^{-}$ $(0.45 \mathrm{mM})$ while $\mathrm{H}_{2} \mathrm{O}_{2}(0-400 \mu \mathrm{M})$ was insufficient to reduce all the $\mathrm{AuCl}_{4}^{-}$, the AuNPs generation probably changed after $\mathrm{H}_{2} \mathrm{O}_{2}$ was consumed completely. However, it was found that the AuNPs generation reached a plateau after 10 minutes and then the developed color changed very slowly. After the color developing for $60 \mathrm{~min}, 25 \mu \mathrm{M} \mathrm{H}_{2} \mathrm{O}_{2}$ still can be differentiated by the naked eye (Figure $3(\mathrm{a})$ ) and $5 \mu \mathrm{M} \mathrm{H}_{2} \mathrm{O}_{2}$ by spectrophotometry (Figure 3(b)). These results demonstrate that this one-pot reaction has a wide window for analysis of $\mathrm{H}_{2} \mathrm{O}_{2}$, which can facilitate practical applications. When $\mathrm{H}_{2} \mathrm{O}_{2}$ was detected by a spectrophotometer, a linear range of $2-400 \mu \mathrm{M}\left(R^{2}=99.6 \%\right)$ was obtained and the detection limit $(S / N=3)$ is evaluated as $0.5 \mu \mathrm{M}$ (Figure 4 ). The sensitivity of the developed method here is higher or comparable with that of some other nanoparticle-based colorimetric $\mathrm{H}_{2} \mathrm{O}_{2}$ sensors $[7,14,15]$.

To further understand the interesting property of this visual $\mathrm{H}_{2} \mathrm{O}_{2}$ sensor, we observed the shapes of the GNPs reduced by the different concentration of $\mathrm{H}_{2} \mathrm{O}_{2}$. Branched GNPs comprising branched nanocrystals with about $10 \mathrm{~nm}$ dimension were found by the reduction of $100 \mu \mathrm{M} \mathrm{H}_{2} \mathrm{O}_{2}$ (Figures 5(a)-5(e)). GNP dimers comprising 20-25 nm branches can be found by the reduction of $400 \mu \mathrm{M} \mathrm{H}_{2} \mathrm{O}_{2}$ (Figure 5(f)), while dispersed quasi-spherical GNPs in the dimension of $30-40 \mathrm{~nm}$ can be found by the reduction of 


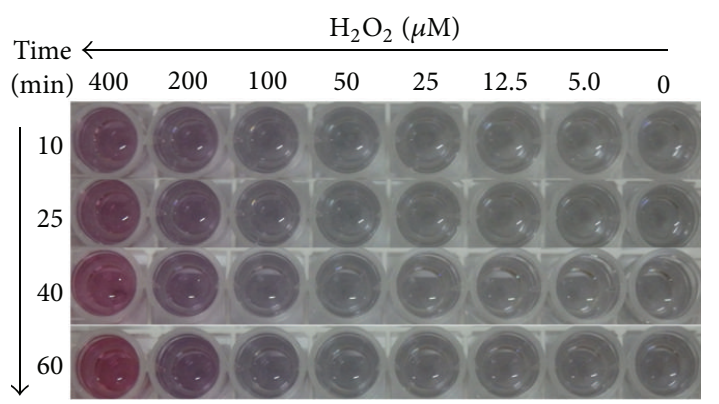

(a)

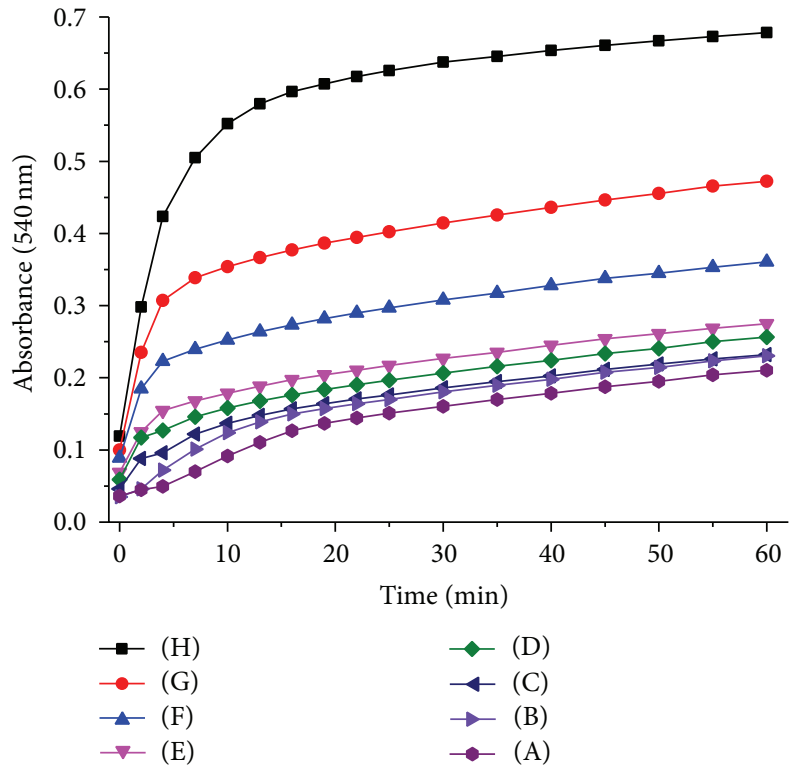

(b)

FIGURE 3: $\mathrm{H}_{2} \mathrm{O}_{2}(0-400 \mu \mathrm{M})$ reduction of GNPs over time: (A) $0 \mu \mathrm{M}$, (B) $5 \mu \mathrm{M}$, (C) $12.5 \mu \mathrm{M}$, (D) $25 \mu \mathrm{M}$, (E) $50 \mu \mathrm{M}$, (F) $100 \mu \mathrm{M},(\mathrm{G})$ $200 \mu \mathrm{M}$, and $(\mathrm{H}) 400 \mu \mathrm{M} \mathrm{H}_{2} \mathrm{O}_{2}$.

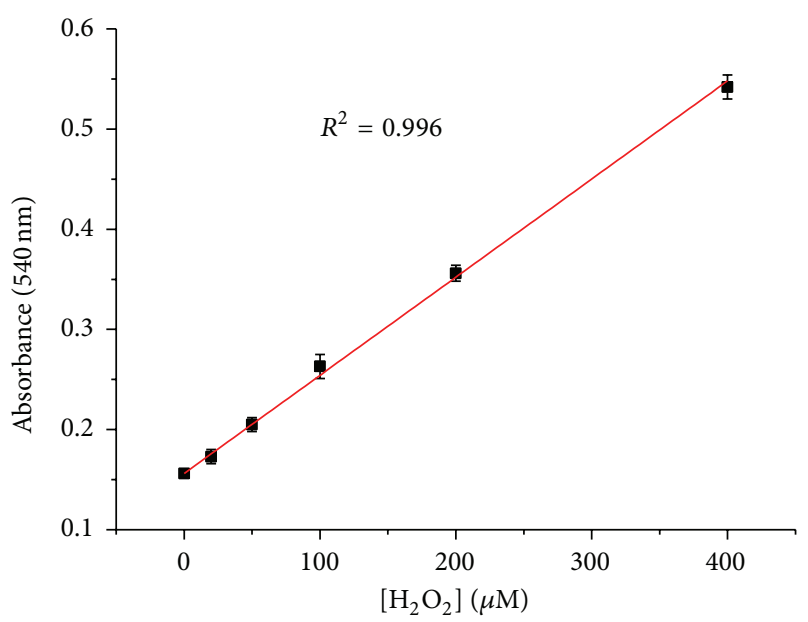

Figure 4: Calibration curve for quantitative detection of $\mathrm{H}_{2} \mathrm{O}_{2}$. $\mathrm{H}_{2} \mathrm{O}_{2}$ reduction of GNPs kept for $10 \mathrm{~min}$. The error bars represent standard derivations.

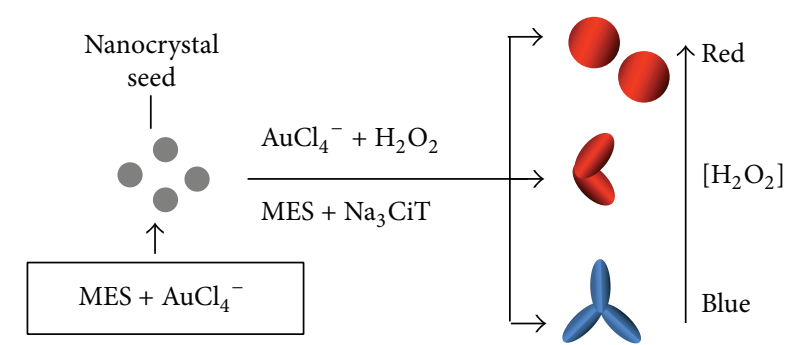

Scheme 1: Cartoon of the generation of different shapes of GNPs.

$600 \mu \mathrm{M} \mathrm{H}_{2} \mathrm{O}_{2}$ (Figure 5(g)). This finding is probably useful in controllable synthesis of branched GNPs, which is very useful for the fabrication of nanosensors, multiple-terminal devices, and so forth [16].

The entirely different shapes of GNPs generated in the presence of varied concentrations of $\mathrm{H}_{2} \mathrm{O}_{2}$ suggest that two processes at least will happen in this $\mathrm{MES}-\mathrm{Na}_{3} \mathrm{Cit}-\mathrm{AuCl}_{4}{ }^{-}$$\mathrm{H}_{2} \mathrm{O}_{2}$ reaction (Scheme 1). One process involves the reduction of $\mathrm{AulCl}_{4}{ }^{-}$by MES. Since, with the addition of $\mathrm{Na}_{3} \mathrm{Cit}$ and in the absence of $\mathrm{H}_{2} \mathrm{O}_{2}$, MES still produced weak reduction of $\mathrm{AuCl}_{4}^{-}$, MES can act like an "initiator" (Figure 1(b)). MES also functions like other zwitterionic molecules under certain conditions since many Good's buffers can serve as shape-directing agents in synthesis of branched gold nanocrystals [16]. Another process involves the reduction of $\mathrm{AulCl}_{4}{ }^{-}$by MES, which mainly depends on the reduction of $\mathrm{AuCl}_{4}{ }^{-}$by $\mathrm{H}_{2} \mathrm{O}_{2}$. With the addition of increased $\mathrm{H}_{2} \mathrm{O}_{2}$, the enlargement of gold nanoparticles gradually overwhelms the generation of the branched gold nanocrystals.

Detection of Glucose. Numerous oxidases can produce $\mathrm{H}_{2} \mathrm{O}_{2}$ upon the oxidation of the respective substrates by $\mathrm{O}_{2}$. It suggests that this $\mathrm{AuCl}_{4}{ }^{-} / \mathrm{MES} / \mathrm{Na}_{3} \mathrm{Cit}$ system can probably be employed as an effective tool for the visual sensing of oxidases and their substrates. We have applied this system to detect glucose by using glucose oxidase (GOD) and glucose $/ \mathrm{O}_{2}$ as $\mathrm{H}_{2} \mathrm{O}_{2}$ producing system. Figure 6(a) shows the visual detection results of glucose in this reaction system. The solution color deepened gradually as the glucose concentration was increased. Light blue solution was produced corresponding to $0.03-0.1 \mathrm{mM}$ glucose while purple solution was produced corresponding to $0.3-1.0 \mathrm{mM}$ glucose. After glucose concentration increased to above $3.0 \mathrm{mM}$, the produced solutions changed to bright red wine. This color change can be distinguished clearly by the naked eye. This sensitivity is comparable with the method reported recently but shows more distinguishable and controllable color development model [17]. Figure 6(b) showed that the absorbance intensity of reaction solutions increased gradually as the glucose concentration increased. The detection limit of $0.01 \mathrm{mM}$ glucose $(S / N=3)$ and linear range from 0.01 to $0.3 \mathrm{mM}$ were obtained by spectrophotometry (Figure 6(b)). The sensitivity is higher than or comparable with that of the colorimetric methods recently reported $[7,14,17,18]$.

Detection of Catalase. Catalase is very important enzyme in protecting the cell from oxidative damage by reactive 


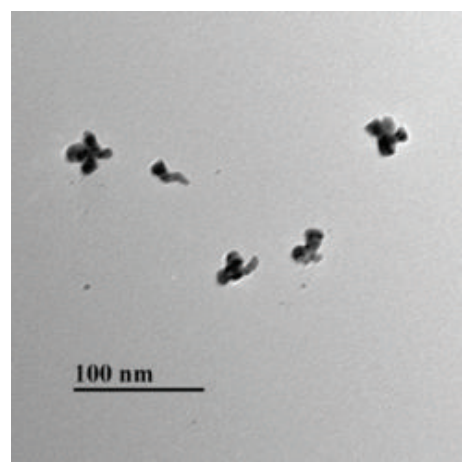

(a)

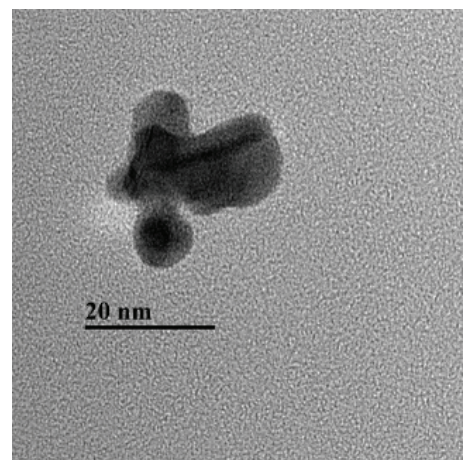

(d)

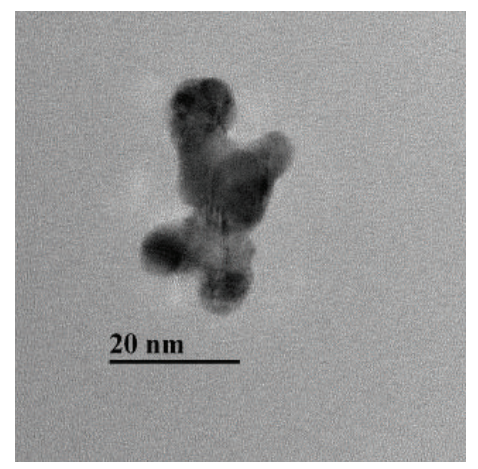

(b)

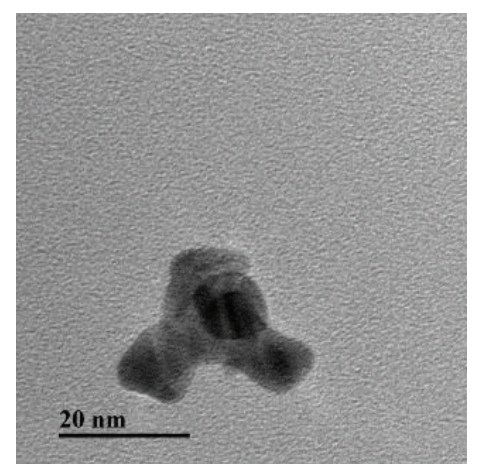

(e)

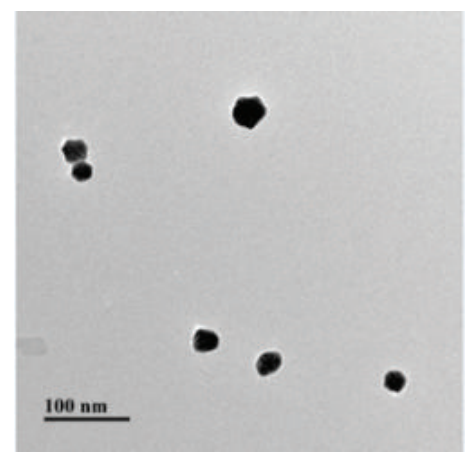

(g)

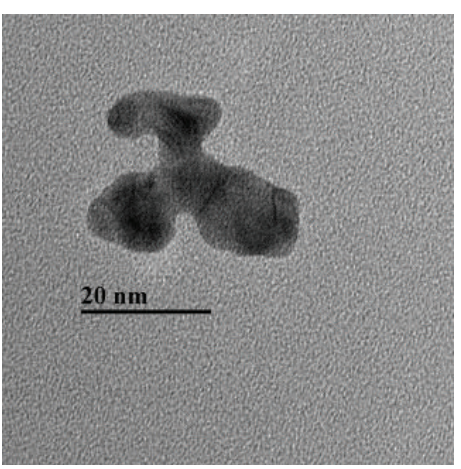

(c)

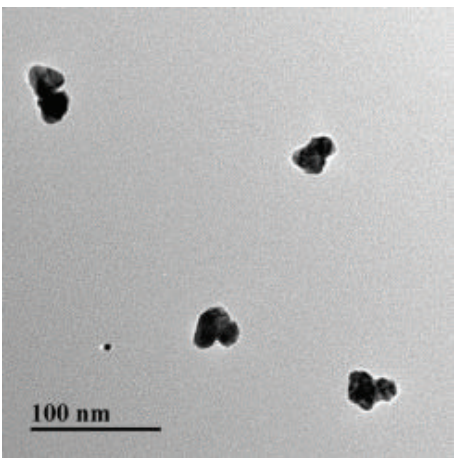

(f) oxygen species. Catalase is also a key indicator of mastitis disease in milk $[19,20]$. Thus, facile detection catalase will be useful in many fields. Since catalase can decompose $\mathrm{H}_{2} \mathrm{O}_{2}$ efficiently, coupling this decomposition with the above $\mathrm{AuCl}_{4}{ }^{-} / \mathrm{MES} / \mathrm{Na}_{3} \mathrm{Cit}$ reaction can probably be utilized to probe the activity of catalase. As expected, the performance adverse to that of the above $\mathrm{H}_{2} \mathrm{O}_{2}$ detection was found (Figure 7(a)). As the concentration of catalase increased from $0.03 \mathrm{U} / \mathrm{mL}$ to $21.0 \mathrm{U} / \mathrm{mL}$, different solution colors from wine red and purple to light blue were demonstrated. By the naked eye, $0.3 \mathrm{U} / \mathrm{mL}$ of catalase can be clearly distinguished. In addition, the detection limit of $0.026 \mathrm{U} / \mathrm{mL}$ catalase $(S / N=$ 3) can be achieved by spectrophotometry (Figure 7(b)). The sensitivity of the "naked eye" or colorimetric methods developed here is higher than the surface plasmon resonance
(SPR) method [20] and amperometric biosensor reported recently [19] or comparable with that of some expensive commercial available kits for catalase detection.

\section{Conclusions}

In conclusion, gold nanoparticles (GNPs) with different shapes can be generated in the reduction of $\mathrm{HAuCl}_{4}$ by varied concentration of $\mathrm{H}_{2} \mathrm{O}_{2}$ with the assist of dual-molecules, 2(N-morpholino)ethanesulfonic acid (MES) and sodium citrate. This simple $\mathrm{AuCl}_{4}{ }^{-} / \mathrm{MES} / \mathrm{Na}_{3} \mathrm{Cit} / \mathrm{H}_{2} \mathrm{O}_{2}$ reaction system can also be employed to sensitively detect $\mathrm{H}_{2} \mathrm{O}_{2}$ by "naked eye" and has been applied to probe substrate or enzyme in oxidase-based reactions. This interesting $\mathrm{H}_{2} \mathrm{O}_{2}$ sensor is ascribed to a proposed "dual-molecules assist" mechanism. 


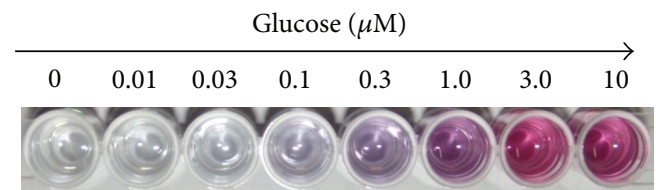

(a)

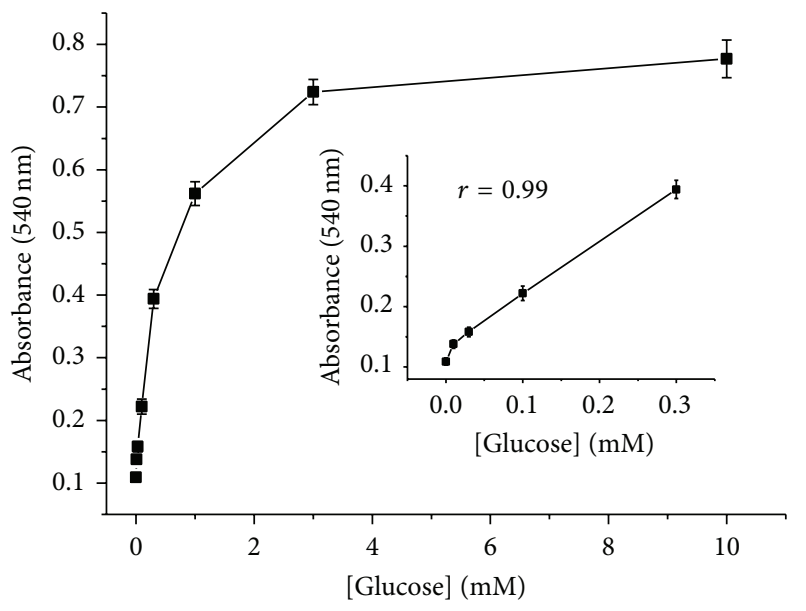

(b)

FIGURE 6: Generation of nanoparticle solutions with different colors depends on the concentration of glucose. (a) Photograph showing the generation of GNP solutions with different colors and intensities. (b) Plots of absorbance values of GNP solutions against the concentration of glucose. Inset: linear relationship between absorbance values and glucose concentrations.

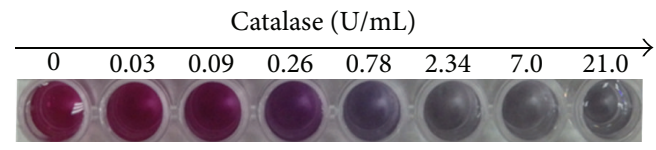

(a)

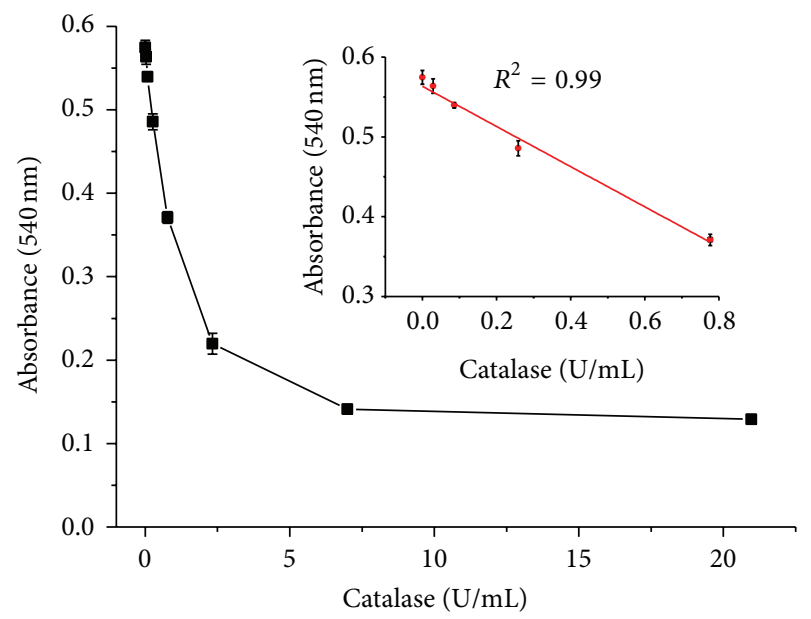

(b)

FIGURE 7: Generation of nanoparticle solutions with different colors depends on the concentration of catalase. (a) Photograph showing the generation of GNP solutions with different colors and intensities. (b) Plots of absorbance values of GNP solutions against the concentration of catalase. Inset: linear relationship between absorbance values and catalase concentrations.
Since many other Good's buffers besides MES can reduce $\mathrm{AuCl}_{4}{ }^{-}$and many other molecules besides sodium citrate function as stabilizers in the synthesis of GNPs, a great deal of combination can be explored to optimize the performance of these $\mathrm{H}_{2} \mathrm{O}_{2}$ and oxidase-based sensors. The developed catalase sensor can probably be utilized to fabricate ultrasensitive ELISA methods for various analytes, which is now being studied by our group. Additionally, branched anisotropic GNPs can be synthetized via this "dual-molecules assist" strategy.

\section{Conflict of Interests}

The authors declare that there is no conflict of interests regarding the publication of this paper.

\section{Acknowledgments}

This work was supported by the National Natural Science Foundation of China (31371767), the 12th Five Years Key Programs (2012BAK08B01), the Natural Science Foundation of Jiangsu Province (BK20141108), and the Research Program of State Key Laboratory of Food Science and Technology, Jiangnan University (SKLF-ZZA-201202).

\section{References}

[1] L. Xu, H. Kuang, C. Xu, W. Ma, L. Wang, and N. A. Kotov, "Regiospecific plasmonic assemblies for in Situ Raman spectroscopy in live cells," Journal of the American Chemical Society, vol. 134, no. 3, pp. 1699-1709, 2012.

[2] L. Wang, L. Xu, H. Kuang, C. Xu, and N. A. Kotov, "Dynamic nanoparticle assemblies," Accounts of Chemical Research, vol. 45, no. 11, pp. 1916-1926, 2012.

[3] J. He, Y. Liu, T. C. Hood, P. Zhang, J. Gong, and Z. Nie, "Asymmetric organic/metal(oxide) hybrid nanoparticles: synthesis and applications," Nanoscale, vol. 5, no. 12, pp. 5151-5166, 2013.

[4] D. Liu, Z. Wang, and X. Jiang, "Gold nanoparticles for the colorimetric and fluorescent detection of ions and small organic molecules," Nanoscale, vol. 3, no. 4, pp. 1421-1433, 2011.

[5] Y. Zhou, S. Wang, K. Zhang, and X. Jiang, "Visual detection of copper(II) by azide- and alkyne-functionalized gold nanoparticles using click chemistry," Angewandte Chemie International Edition, vol. 47, no. 39, pp. 7454-7456, 2008.

[6] H. Jans and Q. Huo, "Gold nanoparticle-enabled biological and chemical detection and analysis," Chemical Society Reviews, vol. 41, no. 7, pp. 2849-2866, 2012.

[7] H. Kuang, W. Chen, W. Yan et al., "Crown ether assembly of gold nanoparticles: melamine sensor," Biosensors and Bioelectronics, vol. 26, no. 5, pp. 2032-2037, 2011.

[8] Y. Xiao, V. Pavlov, S. Levine, T. Niazov, G. Markovitch, and I. Willner, "Catalytic growth of $\mathrm{Au}$ nanoparticles by $\mathrm{NAD}(\mathrm{P}) \mathrm{H}$ cofactors: optical sensors for $\mathrm{NAD}(\mathrm{P})^{+}$-dependent biocatalyzed transformations," Angewandte Chemie, vol. 43, no. 34, pp. 45194522, 2004.

[9] M. Zayats, R. Baron, I. Popov, and I. Willner, "Biocatalytic growth of Au nanoparticles: from mechanistic aspects to biosensors design," Nano Letters, vol. 5, no. 1, pp. 21-25, 2005.

[10] D. Kim, W. L. Daniel, and C. A. Mirkin, "Microarray-based multiplexed scanometric immunoassay for protein cancer markers 
using gold nanoparticle probes," Analytical Chemistry, vol. 81, no. 21, pp. 9183-9187, 2009.

[11] S. Cai, K. Lao, C. Lau, and J. Lu, “'Turn-on’ chemiluminescence sensor for the highly selective and ultrasensitive detection of $\mathrm{Hg} 2+$ ions based on interstrand cooperative coordination and catalytic formation of gold nanoparticles," Analytical Chemistry, vol. 83, no. 24, pp. 9702-9708, 2011.

[12] H. Li, X. Ma, J. Dong, and W. Qian, "Development of methodology based on the formation process of gold nanoshells for detecting hydrogen peroxide scavenging activity," Analytical Chemistry, vol. 81, no. 21, pp. 8916-8922, 2009.

[13] S. Liao, Y. Qiao, W. Han et al., "Acetylcholinesterase liquid crystal biosensor based on modulated growth of gold nanoparticles for amplified detection of acetylcholine and inhibitor," Analytical Chemistry, vol. 84, no. 1, pp. 45-49, 2012.

[14] Y. Jv, B. Li, and R. Cao, "Positively-charged gold nanoparticles as peroxidiase mimic and their application in hydrogen peroxide and glucose detection," Chemical Communications, vol. 46, no. 42, pp. 8017-8019, 2010.

[15] X. Liu, H. Xu, H. Xia, and D. Wang, "Rapid seeded growth of monodisperse, quasi-spherical, citrate-stabilized gold nanoparticles via $\mathrm{H}_{2} \mathrm{O}_{2}$ reduction," Langmuir, vol. 28, no. 38, pp. 13720 13726, 2012.

[16] R. De La Rica and M. M. Stevens, "Plasmonic ELISA for the ultrasensitive detection of disease biomarkers with the naked eye," Nature Nanotechnology, vol. 7, no. 12, pp. 821-824, 2012.

[17] P. Gobbo, M. J. Biondi, J. J. Feld, and M. S. Workentin, "Arresting the time-dependent $\mathrm{H}_{2} \mathrm{O}_{2}$ mediated synthesis of gold nanoparticles for analytical detection and preparative chemistry," Journal of Materials Chemistry B, vol. 1, no. 33, pp. 4048-4051, 2013.

[18] R. de la Rica and M. M. Stevens, "Plasmonic ELISA for the detection of analytes at ultralow concentrations with the naked eye," Nature Protocols, vol. 8, no. 9, pp. 1759-1764, 2013.

[19] C. Engelbrekt, K. H. Sørensen, J. Zhang, A. C. Welinder, P. S. Jensen, and J. Ulstrup, "Green synthesis of gold nanoparticles with starch-glucose and application in bioelectrochemistry," Journal of Materials Chemistry, vol. 19, no. 42, pp. 7839-7847, 2009.

[20] M. Grzelczak, J. Pérez-Juste, P. Mulvaney, and L. M. Liz-Marzán, "Shape control in gold nanoparticle synthesis," Chemical Society Reviews, vol. 37, no. 9, pp. 1783-1791, 2008. 

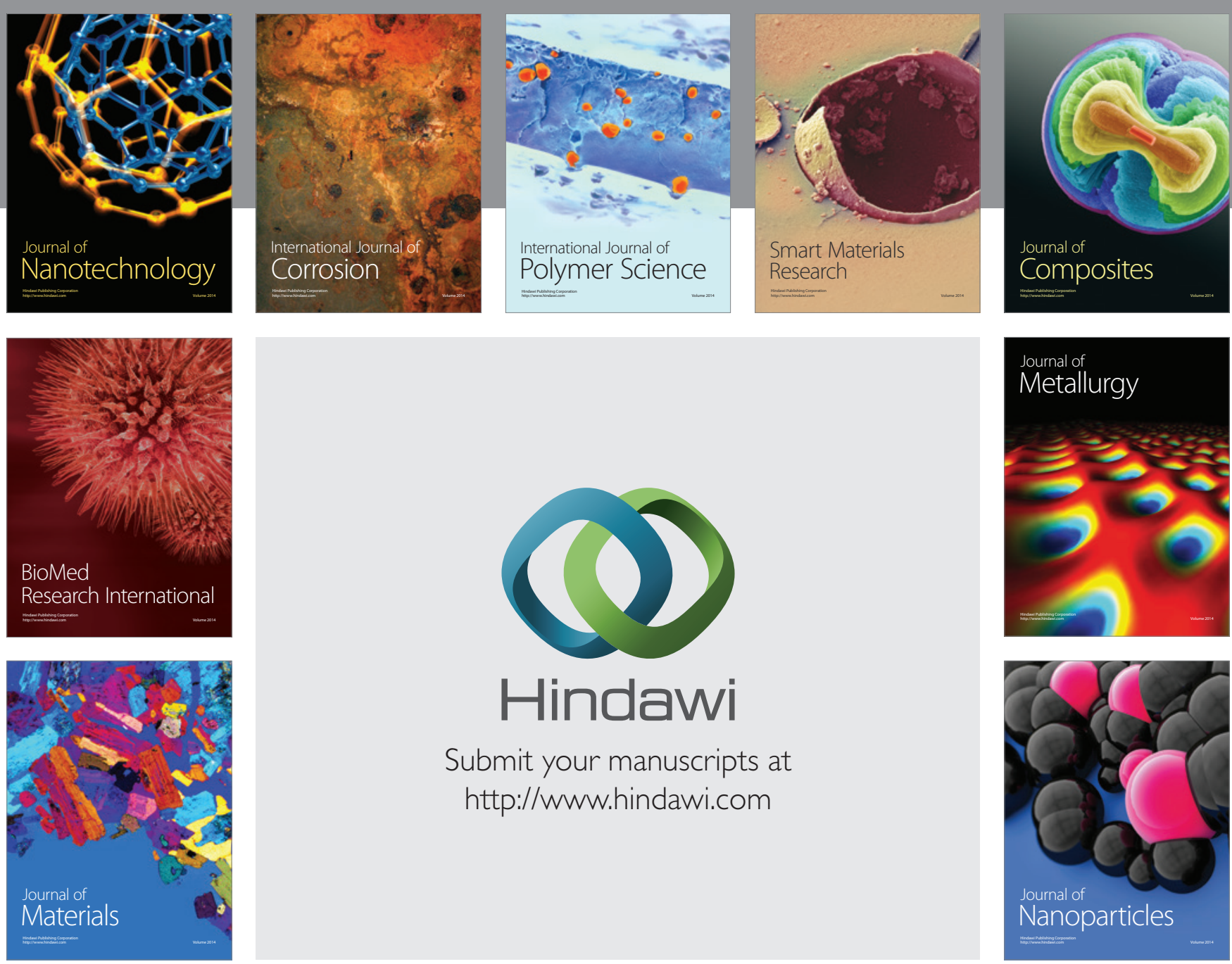

Submit your manuscripts at http://www.hindawi.com
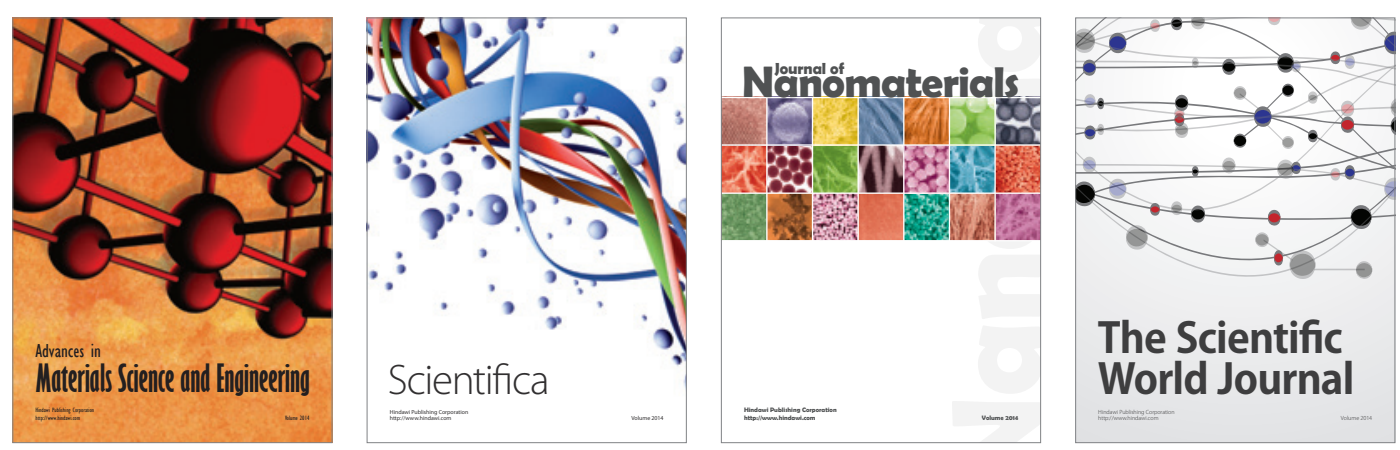

\section{The Scientific World Journal}
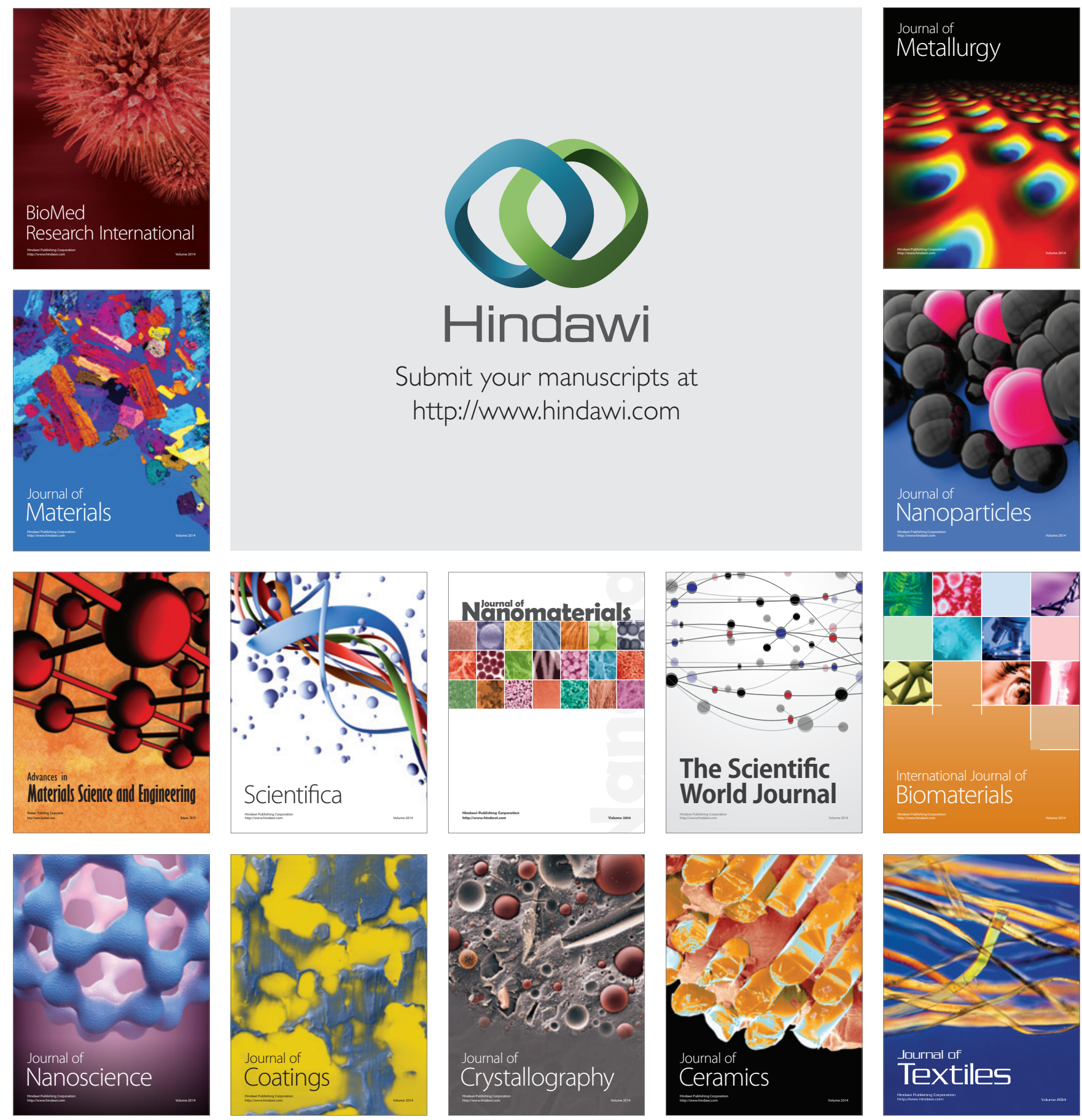